\title{
Sentinel-1 data for flood disaster monitoring and assessment: case studies in Romania
}

\author{
Anisoara Irimescu ${ }^{1, a}$, Denis Mihailescu ${ }^{1}$ and Gheorghe Stancalie ${ }^{1}$ \\ ${ }^{1}$ National Meteorological Administration, 97, Sos. Bucuresti-Ploiesti, 013686, Bucharest, Romania
}

\begin{abstract}
Floods represent one of the most significant natural disaster in Romania. The paper describes the main stages of image processing, for flood disaster monitoring and assessment in radar domain: the processing chain involves the stages starting with image calibration, speckle filtering, segmentation/histogram analysis and terrain corrections. The results of satellite data processing were integrated in a GIS environment to obtain standardized, cartographic products. The satellite-based flood monitoring includes: mapping the maximum flood extent, flooded area classification, flood evolution maps etc., while the damage assessment covers: flooded areas, affected population, categories of land use and communication infrastructure. The paper presents recent flood case studies of March 2018, in the upper part of the Olt basin, located in the central part of Romania, based on Sentinel-1 (S1) satellite imageries and ancillary in-situ data (hydrological and meteorological measurements). The S1 satellite provide high temporal frequency (daily) and good spatial resolution (10-11 m), which have been used as a primary data source for flood disaster monitoring (S1) and damage assessment (Corine Land Cover, 2018). In order to map the flood extent, the Synthetic Aperture Radar (SAR) sensor of $\mathrm{S} 1$ is used due to all-weather monitoring capability and its large coverage.
\end{abstract}

\section{Introduction}

Floods are one of the most important disaster events in the World due to their loss of human lives and economic consequences (EC, 2007; EEA, 2010). Floods are generated by extreme weather events (heavy or long time rain, storm and snowmelt) correlated with human-driven elements: waterways management (dams, levees and reservoirs), urbanization increase (impermeable surfaces, natural drainage system disturbance, settlements development in the floodplain) and natural elements (soil properties, land use/land cover, slope), (Szopos and Czellecz, 2017).

In the last decades, more ecosystems and human systems are exposed and vulnerable to the impacts of climate changes (floods, droughts, heat waves, wildfires etc.) according to the last IPCC report (2014). Climate change conducts to increase the frequency of flood events occurrence. Also, the rapid urbanization causes imperfections in city planning, such as insufficient considerations of the environmental factors and the lack of proper infrastructure development (Tavus et al., 2018). Also, the more settlements develop in the floodplains, the more vulnerable to the hydrological events they become (Jongman et al., 2012; Neundlinger, 2012).

As a means of emergency response after a flooding event or inland inundation, flood mapping helps to estimate the extent of the flood on a large scale, as well as the affected infrastructure such as roads and settlements and impaired areas of interest for example agricultural regions. This activity is a basis of coordinating appropriate recovery activities, rehabilitation and prevention measures for possible upcoming events (UN-SPIDER).

The advantages of remote sensing information (temporal and spatial coverage, high spatial resolution) coupled with new sensors launch have been increasingly improving the flood mapping methods under difficult situations: clouds cover and steep terrain (Tavus et al., 2018). Satellite observations can regularly provide up-todate information about the danger posed by floods at regional, local or basin level. The data obtained from the satellite sensors are complementary to the in-situ data, but in many cases they can be the only source of information, due, on the one hand, to the lack or shortcomings of the insitu data, and on the other hand, because the satellites provide a unique way of monitoring that cannot be affected by the observed event (Stancalie et al., 2016).

The ESA Sentinels program, by the free and open-data policy, offers a valuable source of rapid synoptic spatiotemporal information at the local or regional scale during and after the flood emergency situations (Caballero et al., 2019).

Flood monitoring demonstrates the synergistic use of observations from different satellite sensors, with a careful analysis of the spatial / temporal resolution and time of review specific to each satellite, allowing optimal observation and integration of information (ESA, 2015). While the optical images have a great potential for flood 
mapping with high accuracy (Shen et al., 2019; Nandi et al., 2017; Joyce et al., 2009), their use is limited due to high cloud coverage during the flood period (Uddin et al., 2019). In the last two decades, the Synthetic Aperture Radar sensor (SAR) have been used for flood mapping and monitoring, based on X- (TerraSAR), C- (Sentinel-1, ERS-1/2, Envisat ASAR, Radarsat-1), and L- (SEASAT1, JERS-1, ALOS PALSAR) band sensors.

The usefulness of the Sentinel-1 C-band (central frequency of $5.404 \mathrm{GHz}$ ) for flood extend mapping has been investigated by DeVries et al., 2020; Shen et al., 2019; Tarvus et al., 2019; Uddin et al., 2019; Bioresita et al., 2018; Martinis, 2017; Twele et al., 2016). Sentinel-1 with the available SAR and its spatial resolution and short temporal baselines has the potential to facilitate the monitoring of surface water changes, which are dynamic in space and time (Bioresita et al., 2018).

The use of remote sensing data to support the rapid mapping and flood disaster management is strengthening by global initiatives, such as The International Charter, The Dartmouth Flood Observatory, Copernicus Emergency Management Service etc. (Schumann, 2017).

Causes and impacts of flood events in Romania, using the EO data, have been the main goal of international projects such as: Monitoring of extreme flood events in Romania and Hungary using EO data (nato.inmh.ro), Platform for Geoinformation in support of disaster management (geodim.meteoromania.ro), or analysed in research studies such as: Craciunescu et al., 2009; Irimescu et al., 2009; Stancalie et al., 2009; Negula et al., 2013; Craciunescu et al., 2016, Stancalie et al., 2016.

In Romania, flood recorded 39 events, 239 casualties and a total of 224,000 people affected since 2000 . It is noted that the years 2005 ( 79 human lives losses) and 2006 (flows of about $15,800 \mathrm{mc} / \mathrm{s}$ on the Danube and 51 deaths) as years with historical records. In 2018, two major flood events occurred with a total of 2700 people affected (CRED, 2019; EM-DAT database).

\section{Study area}

The Olt River Basin is located in the central-southern part of Romania (Figure 1).

Its total surface is $24,050 \mathrm{~km}^{2}$ and $615 \mathrm{~km}$ length of the main course (ICPDR). Its springs are in the Eastern Carpathian Mountains, from about 1800 m.a.s.l., flowing exclusively through Romania to its mouth at the Danube River. The upper river basin belongs to the mountain area and has a surface of about $6,340 \mathrm{~km}^{2}$. The mean altitude is $600-750$ m.a.s.1., while the mean slope is $2 \%$ (ROWATER). The Olt crosses a succession of mountain depressions (Ciucului, Bârsei, Făgăraş) separated by the gorges (Tuşnad, Racoş) following the geological structure (constituted of volcanic, crystalline and sedimentary rocks of the age of Triassic, Jurassic and Cretaceous). The presence of volcanic rocks has favoured the emergence of many mineral springs.

From the climatic point of view, Olt's upper basin is under the influence of atmospheric oceanic circulation. Thus, from the last climatic period (1981-2010), the annual average rainfall varies from $500 \mathrm{l} / \mathrm{sqm}$ to $1000 \mathrm{l} / \mathrm{sqm}$, the annual average temperatures varies from $6^{\circ} \mathrm{C}$ in the depression areas to $2^{\circ} \mathrm{C}$ on the mountain ridges, while the mean number of days with snow on the ground varies from 65 to 195 days (NMA).

In this sector, the basin has an accentuated symmetry with water courses that are almost perpendicular to the Olt River. The tributaries (around 70 in this sector) are generally small rivers with areas ranging from 20 to 100 $\mathrm{km}^{2}$ and lengths less than $20 \mathrm{~km}$, except for Fişag, Râul Negru, Bârsa, Homorod - Ciucaș, Șercaia on the left banks and Baraolt, Cormoş, Homorod on the right banks.

The water sources are: the snowmelt in mountain regions and rainfalls. When these two sources act simultaneously, they can increase the discharge and lead to flooding. The mean discharge varies from $1.52 \mathrm{~m}^{3} / \mathrm{s}$ at Tomeşti (close to the river springs) to $60.3 \mathrm{~m}^{3} / \mathrm{s}$ at Făgăraş (ROWATER) (end of the studied area), with a maximum value in April and a minimum in January and September November. The highest flows in the upper part of the basin have been recorded in 1970, 1972, 1975, 1981, 1984, 2015 and 2018 (ICPDR).

In the upper Olt basin there are $642.1 \mathrm{~km}$ dikes and 324.4 $\mathrm{km}$ regulations of river beds to protect against floods: towns, industrial units, houses, agricultural lands, roads, bridges, railways etc. (ICPDR).

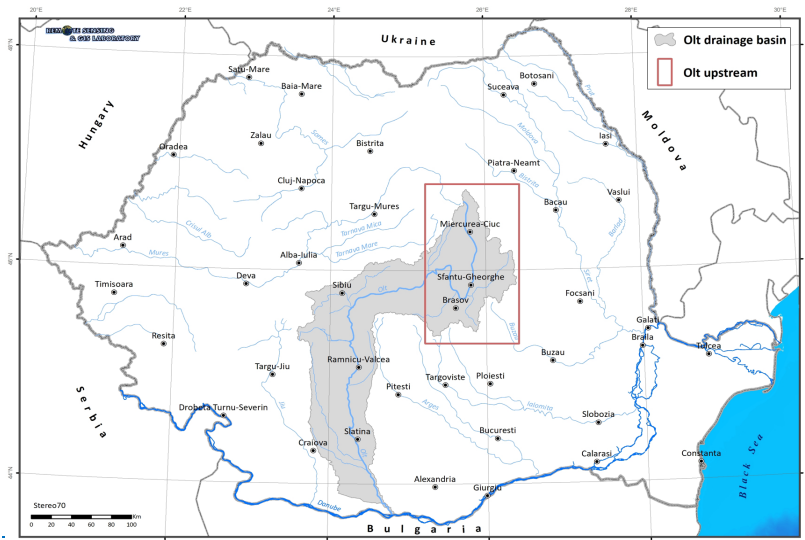

Figure 1. Geographical position of Olt River in Romania. The red square delineates the upper part of the basin.

\section{Data \& Methodology}

Development of algorithms for flood detection and mapping systems is researched intensively lately (Reksten et al., 2019; D’Addabbo et al., 2016; Twele et al., 2016; Martinis et al., 2015; Refice et al., 2014; Giustarini et al., 2013; Serpico et al., 2012; Martinis et al., 2009).

Images acquired using microwaves provide information on the geometric and dielectric properties of a surface or on volumes, which mainly depend on the surface roughness, the type of material (concrete, wood, and iron, organic) and humidity. If a surface has a high roughness, the backscattering and intensity of the object's brightness on the image is high. A calm aquatic surface will appear black, and one affected by waves will appear bright due to the height of the waves.

The main used techniques for flood detection, based on SAR data, are: 
- change-detection technique (Reksten et al., 2019; Pirrone et al., 2016; Long et al., 2014; Brisco et al., 2013; Giustarini et al., 2013; Gan et al., 2012; Huang et al., 2011; Inglada and Mercier 2007);

- histogram thresholding or clustering (Giustarini et al., 2013; Martinis et al., 2009 Inglada and Mercier 2007);

- radiometric thresholding (Matgen et al., 2011);

- the application of neural networks in a grid system (Kussul et al., 2008);

- RGB combination (Amitrano et al., 2019; Carreño Conde and De Mata Muñoz, 2019; Perrou et al., 2018; Tavus et al., 2018).

- fractal dimensioning of multi-temporal images (Huang et al. 2011);

- pixel-based segmentation (Martinis et al., 2009);

- statistical active contouring (Horritt et al., 2001).

Ancillary data are used for flood detection and have been explored in research studies (D'Addabbo et al., 2016; Twele et al., 2016).

Sentinel-1 is part of the European space mission through the European Commission's Copernicus program. It is a C-band Synthetic Aperture Radar (SAR) built on the model of the ERS-1, ERS-2, Envisat and Radarsat radar satellites. Sentinel-1 mission consists of 2 satellites, Sentinel-1A, launched on April 3, 2014, and Sentinel-1B, launched on April 25, 2016, with orbits at 180 degrees and a review period of 6 days.

The instrument operates in two main modes: Interferometric Wide swath (IW) and Wave (WV). IW is the terrain-specific mode and has a scan bandwidth of 250 $\mathrm{km}$ and a resolution of $5 \times 20 \mathrm{~m}$. This mode can scan in three sub-bands, using TOPSAR (Terrain Observation with Progressive Scans SAR) technology, so scanning is done three times, back and forth for a single band, resulting in better quality and higher image homogeneity. The acquisition mode of WV images is used in the marine field and can determine the direction, length and height of waves of the seas and oceans at a resolution of $20 \times 20 \mathrm{~km}$. Other secondary modes are: Stripmap-SM with $5 \times 5 \mathrm{~m}$ resolution (80 km swath) and Extra Wide Swath-EW with 20x40 m resolution (uses TOPSAR technology). All these modes can operate in several polarization schemes, single $(\mathrm{HH}$ or $\mathrm{VV}$ ) or double polarization $(\mathrm{VV}+\mathrm{VH}, \mathrm{HH}+\mathrm{HV})$.

The data products derived from all this modes are:

- Level-0: raw data, unfocused, base for higher level products;

- Level-1 SLC (Single Look Complex): focalized data, geo-referenced with slant-range geometry;

- Level-1 GRD (Ground Range Detected): focalized multi-looked data, projected to ground range using an ellipsoid model;

- Level-2: wind, waves and currents products.

The capabilities of the Sentinel-1 (penetrate through the clouds, rain and night) make it particularly useful for flood monitoring. The images acquired before and after the event, provide immediate information on the spatial extent of the flood and provide support in assessing damage and environmental effects. The C-band SAR Sentinel-1 sensor can deliver images with a spatial resolution of $10 \mathrm{~m}$ in a few hours from the event's production, to help in emergency situations.
GRD level 1 data acquired in high resolution IW (Interferometric Wide) mode 20.4 (rg) x 21.7 (azm) can be used for flood detection. GRD has an ellipsoidal projection that can be corrected using the altitude of the terrain specified in the general description of the product. GRD images are acquired with 2 polarizations ( $\mathrm{VH}$ and $\mathrm{VV}$ ), both in amplitude and intensity, the product having a total of four bands (Figure 2).

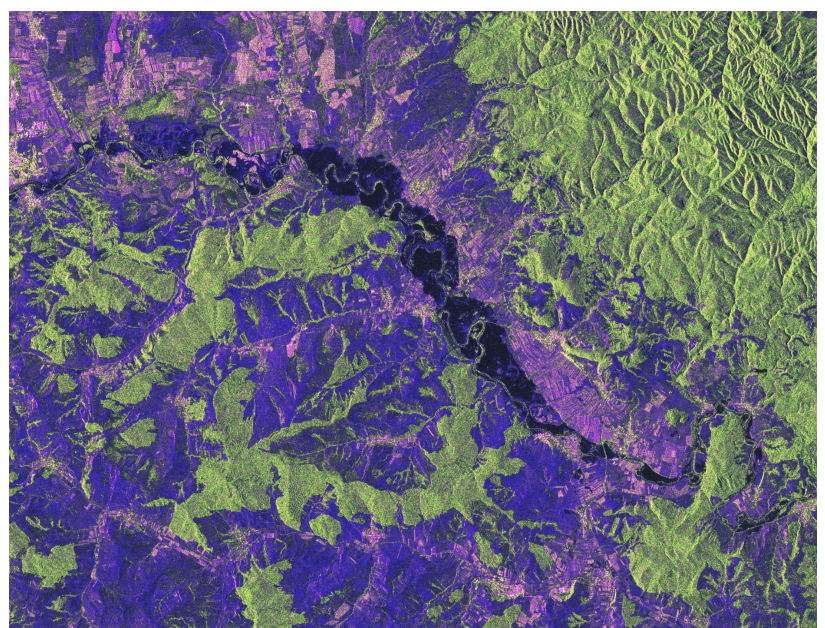

Figure 2. Unprocessed Sentinel-1 data, GRD IW, Dual Pol Ratio Intensity $\mathrm{VV}+\mathrm{VH}$ profile. The image depicted floods (dark blue) over the Olt River, 14 March 2018.

The amplitude represents the magnitude of the displacement of a wave against an average value (it measures the signal strength). The amplitude may involve a complex signal including both magnitude and phase. The intensity is a virtual band and represents the amplitude at the square.

For data sets processing, more tasks are organized into a workflow (Figure 3) that helps to set a path of steps to be followed for achieving the outcomes. The processing data workflow highlights the main operations, with the remarks that some are mandatory (calibration, filtering, terrain correction, etc.) and other are not. When the processing is made on the slower machines, it is recommended to subset the image as close as possible around the study area, for increasing the performance. In this case, removing the border noise can be skipped.

Level-1 SAR data does not include radiometric corrections, which means that the image contains significant radiometric interference.

SAR instruments detect the elapsing time of transmitted pulses received at the instrument, as well as the measured backscatter power and phase information acquired from target objects. During SAR data processing, the measured raw data is focused and converted into a two dimensional image mapping the observation area. Radiometric calibration is necessary to allow a valid conversion of the observed pixel intensity into a physical relevant unit, e.g., radar cross section (RCS), (Schmidt et al., 2020).

For this reason it is necessary to make radiometric corrections, so that the pixel values correctly represent the backscattering of the reflected surface. Non-calibrated data can only be used qualitatively, the calibrated data being necessary for quantitative studies. 


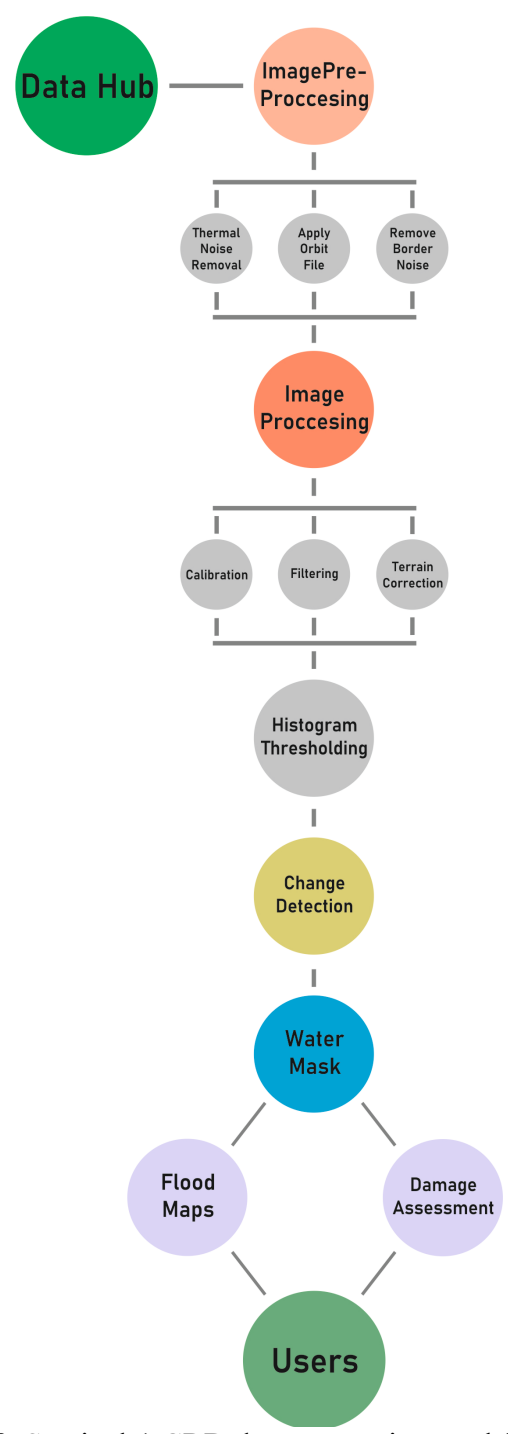

Figure 3. Sentinel-1 GRD data processing workflow.

Radiometric correction is also required to compare SAR data acquired in different seasons or by the same sensor but at different times, in different modes or processed differently.

Radiometric calibration adjusts the measured pixel intensity to a physical property, the radar cross section (RCS). After calibration, this relationship is defined over the entire backscatter range: from low image power (near noise) up to high reflections (below saturation). Based on a proper radiometric calibration, the measured radar backscatter for the Sentinel-1 synthetic aperture radar (SAR) satellite constellation is validated over a wide backscatter range using different target types (Schmidt et al., 2020).

The calibration can be done to both polarizations or only to one (VV or $\mathrm{VH}$ ) and has the result of processing 3 types of bands: sigma $(\sigma)$, gamma $(\gamma)$ and beta $(\beta)$. The calibration is performed according to the following equation:

$$
\operatorname{Value}(i)=\frac{|D N i|^{2}}{A i^{2}}
$$

where:

Value $(\mathrm{i})=\beta 0 \mathrm{i}$ or $\sigma 0 \mathrm{i}$ or $\gamma 0 \mathrm{i}$ or the original $\mathrm{DN}$ values
$\mathrm{Ai}=$ Beta (s) or sigma (s) or gamma (s) or dn (s)

The resulting product will have a single band of the form: Sigma0_VV (if the calibration was done only on VV polarization and only the sigma0 band was chosen as output) and can be viewed in gray tones.

Due to constructive and destructive random phase interference, the signal, even if coherent, is reflected scattered in each cell. For this reason, the texture of the image has a granular appearance (speckle), which affects the quality of the image and makes it difficult to interpret. This effect is not a noise, but an electromagnetic measure used in interferometry (InSAR). The processing parameters include several types of filters that can be used: Lee Sigma, Refined Lee, Lee, Gamma Map etc. Depending on the filter choose, other parameters specific to it can be modified (filter size, Sigma value, etc.). The filter is applied to the radiometrically calibrated band.

The histogram thresholding is performed in order to separate the surfaces covered by water from the other types of land cover. The analysis is done on the previously filtered image. The histogram is visualized in a linear form, which causes the small values to be grouped on a very narrow space, difficult to analyze (statistics are calculated at the sample level). This distribution can be improved by using a logarithmic scale (statistics are calculated precisely at the level of the whole image). For better interpretation and future processing, the sigma band can be converted into decibels $(\mathrm{db})$. The differences between histograms are shown comparatively in Figure 4 (Sentinel-1 image from 14 March 2018).
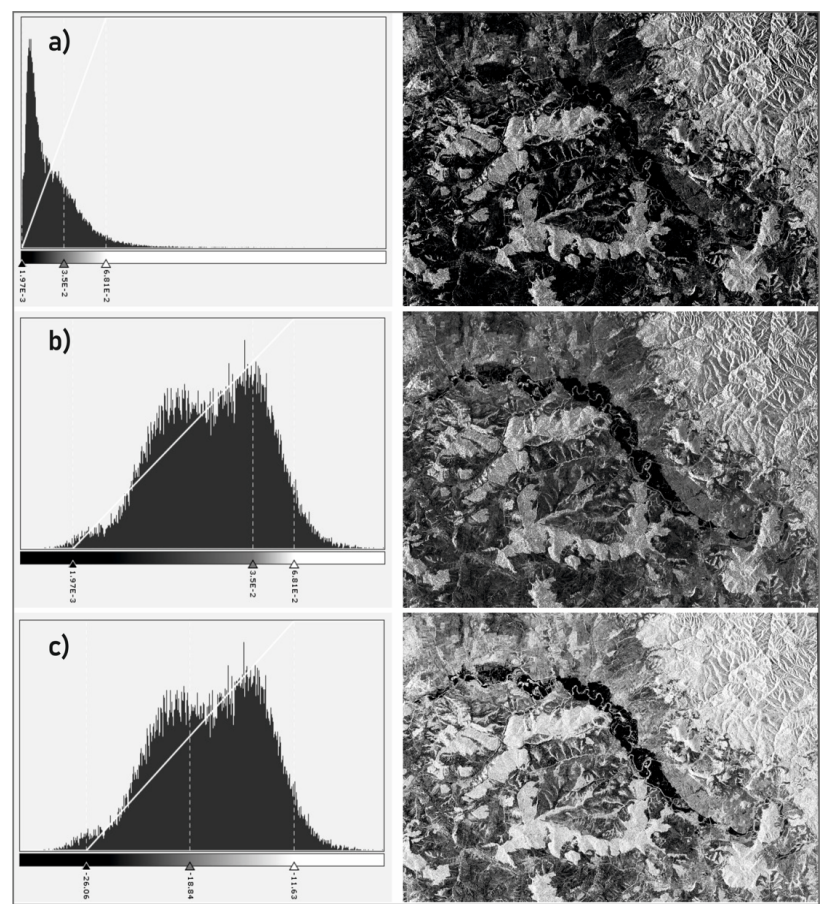

Figure 4. Example of histogram (rough statistics): a) linear; b) logarithmic $\left(\log _{10}\right)$; c) decibels $(\mathrm{db})$.

On the histogram, one or more peaks of the transmitted signal, with different magnitudes, may appear, depending on the analyzed data. The small values correspond to water (due to the low reflection), and the high values correspond to other cover categories (artificial, forest, bare land). There is no single threshold value that separates water 
from other surfaces, it depends on each image separately and the analyst's experience (Figure 5).

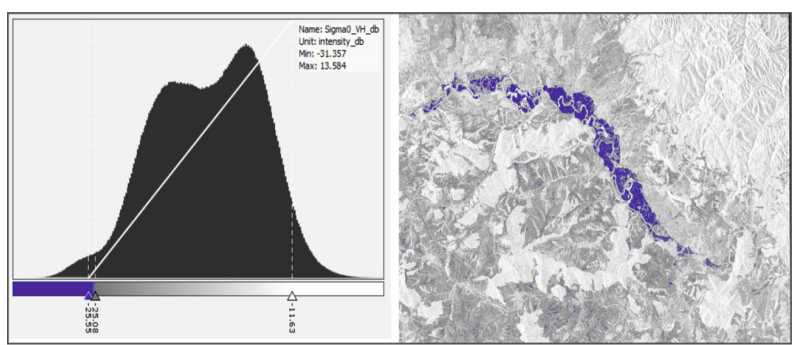

Figure 5. Thresholding water from land on the Sigma band expressed in decibels (db). Image from 14 March 2018.

Due to the topographic variations and sensor bias, the distances in the SAR images can be distorted; especially those that are not oriented to Nadir in relation to the sensor. The field corrections aim to compensate for these distortions so that the geometric representation of the image is as close to reality as possible. Sentinel-1 GRD data have an oblique projection relative to an ellipsoid model, maintaining the original satellite direction and including complete georeferenced information. The pixel value represents the magnitude and the phase information is lost. The pixels have an approximate square shape with a resolution of $10-11 \mathrm{~m}$. The geometric correction is made using a numerical field model (to obtain the altitude values) and different interpolation methods (bilinear interpolation, nearest neighbor, cubic convolution, etc.), to obtain pixel values from the source image.

The water masks extracted (Figure 6) are integrated in GIS (Geographic Information Systems) environments, for post-processing operations (pixel corrections and reclassifications to delimit the reference areas of the water from the flooded surfaces, redesigns etc.) and for final mapping products. From these it can be evaluate and calculate the damages produced, the affected areas, they can be the basis of the intervention actions of the authorities, for reconstruction and not least for the realization of the flood risk maps. Geospatial information, through the creation of online platforms, provides preoperational services that help the emergency management process.

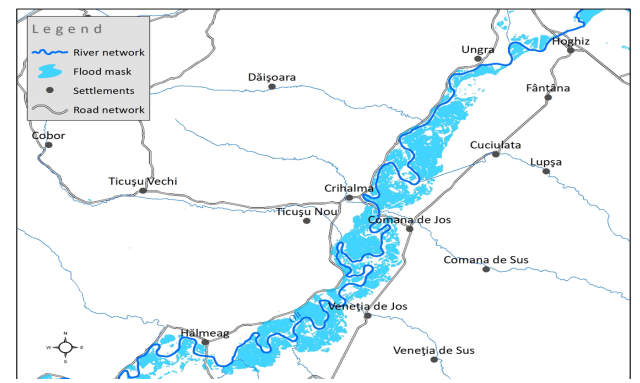

Figure 6. Water mask from 14 March 2018, extracted from Sentinel-1 GRD data

\section{Results \& discussions}

Between 13 and 14 March 2018, most of Europe was under the influence of a vast area of low pressure: a cyclone centered on the Baltic Sea area and a secondary nucleus centered in the north of the Balkan Peninsula. The secondary cyclonic core of the northern Balkan Peninsula evolved into the Western basin of the Black Sea (Odessa Bay). The tandem between these two cyclonic disturbances (with developed frontal systems) generated intense precipitations.

Above Romania was trained a hot air mass (temperatures of $6^{\circ} \ldots 8^{\circ} \mathrm{C}$ at the surface of $850 \mathrm{hPa}$ - about 1500 m.a.s.l.), which determined the predominance of rainfall at 2000 m.a.s.l., favoring the melting of snow, which caused floods at lower altitudes. March was characterized by a precipitation excess, depending on the reference period recording positive deviations of 35-40 $1 /$ sqm, across the country, respectively double the normal quantity for this month of the year.

Inside or nearby the study area, there are 6 meteorological stations: Baraolt, Brasov, Lacauti, Miercurea Ciuc, Sf. Gheorghe and Tg. Secuiesc. Starting with March 13, all 6 stations registered increased quantities of precipitations, with a maximum of $36.6 \mathrm{l} / \mathrm{sqm}$ at Baraolt, located in the middle of area affected. The minimum was registered at Lacauti meteorological station, $19.1 \mathrm{l} / \mathrm{sqm}$. In the next day the values are lower, with a maximum of $25.8 \mathrm{l} / \mathrm{sqm}$ at Lacauti and a minimum of 5.2 1/sqm at Miercurea Ciuc (Figure 7). All the data represents the sum of precipitations in 24 hours.

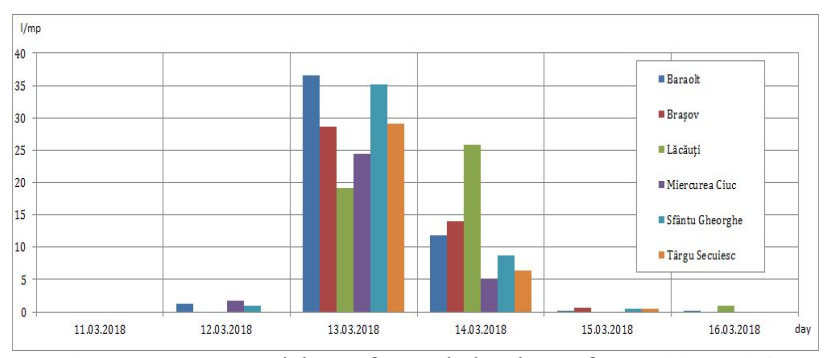

Figure 7. Quantities of precipitations from 11 to 16

March 2018, registered at 6 meteorological stations

The warming trend started at the beginning of the month, with a daily mean air temperature below $0^{\circ} \mathrm{C}(-$ $17.2^{\circ} \mathrm{C}$ at Lacauti, $-9.6^{\circ} \mathrm{C}$ at Baraolt) to positive values near to $10^{\circ} \mathrm{C}$ in less than two weeks (Figure 8), leads to a rapid snow melting. The snow depth on the mountain area that delineates the upper basin of Olt River, was from 10 $\mathrm{cm}$ to $100 \mathrm{~cm}$ on the March 13 .

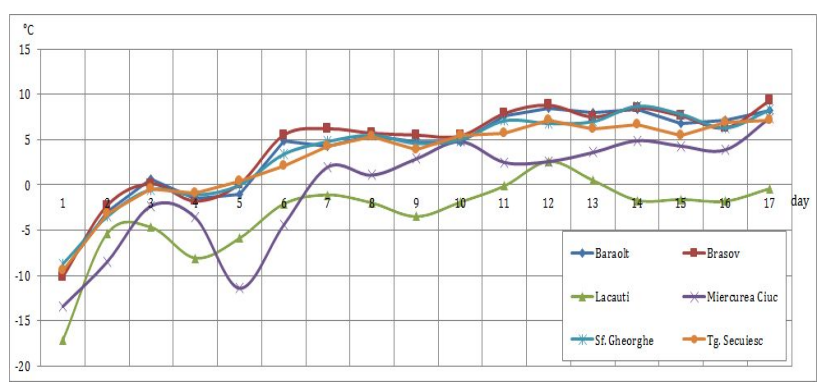

Figure 8. Evolution of air temperature in the first half of March 2018

Following these events, on March 14, floods occurred mainly on the Rivers Olt and Raul Negru. The hydrological station Hoghiz on the Olt River, registered 
over six days (14-19 March 2018), increased flow and overruns of flood level (Table 1).

\begin{tabular}{|c|c|c|c|c|c|c|c|}
\hline \multirow{2}{*}{ Date } & \multicolumn{3}{|c|}{ Defending levels } & $\begin{array}{c}\text { Mean } \\
\text { Flow } \\
\text { March }\end{array}$ & \multicolumn{4}{|c|}{} \\
\cline { 2 - 9 } & $\begin{array}{c}\text { Awarness } \\
(\mathrm{cm})\end{array}$ & $\begin{array}{c}\text { Flood } \\
(\mathrm{cm})\end{array}$ & $\begin{array}{c}\text { Danger } \\
(\mathrm{cm})\end{array}$ & $\begin{array}{c}\text { River } \\
(\mathrm{m} / \mathrm{s})\end{array}$ & $\begin{array}{c}\text { Diagnosis } \\
\text { level } \\
(\mathrm{cm})\end{array}$ & $\begin{array}{c}\text { Flow } \\
(\mathrm{m} 3 / \mathrm{s})\end{array}$ & Overruns (cm) \\
\hline 14.03 .2018 & 300 & 350 & 500 & 58.3 & 434 & 403 & 84 (over flood level) \\
\hline 15.03 .2018 & 300 & 350 & 500 & 58.3 & 466 & 467 & 116 (over flood level) \\
\hline 16.03 .2018 & 300 & 350 & 500 & 58.3 & 455 & 445 & 105 (over flood level) \\
\hline 17.03 .2018 & 300 & 350 & 500 & 58.3 & 435 & 405 & 85 (over flood level) \\
\hline 18.03 .2018 & 300 & 350 & 500 & 58.3 & 415 & 365 & 65 (over flood level) \\
\hline 19.03 .2018 & 300 & 350 & 500 & 58.3 & 393 & 322 & 43 (over flood level) \\
\hline
\end{tabular}

Table 1. Hydrological state of Olt River at Hoghiz station (Source: National Institute of Hydrology and Water Management)

The maximum extend is rich on March 15 when Raul Negru flooded especially agriculture surfaces around Podu Oltului, Dobolii de Jos and to the north-east, Lunca Ozunului up to Reci settlements (Figure 9). 835 ha were affected, most of them being arable land (641 ha), pasture (161 ha) and other types of land cover. Only 0.29 ha of urban areas were flooded.

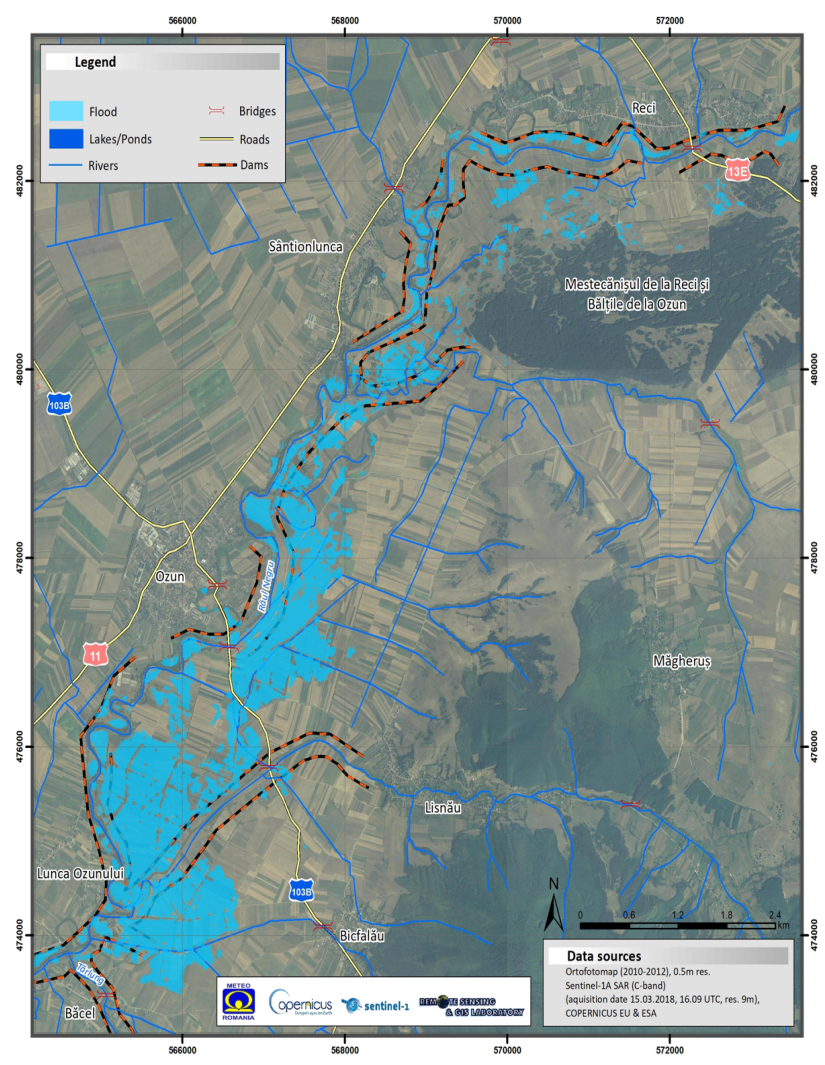

Figure 9. Floods on Raul Negru, upstream of Lunca Ozunului (14 March 2018)

On the Olt River, floods covered a bigger surface, over 1400 ha were affected. The extention was from the city of Baraolt downstream close to the city of Fagaras. The center part of the flood is represented in Figure 10.

The arable land was most affected, with 913 ha flooded; also pasture with 396 ha, the rest being other types of agriculture land, forest or urban areas. No casualties were registered during this event.

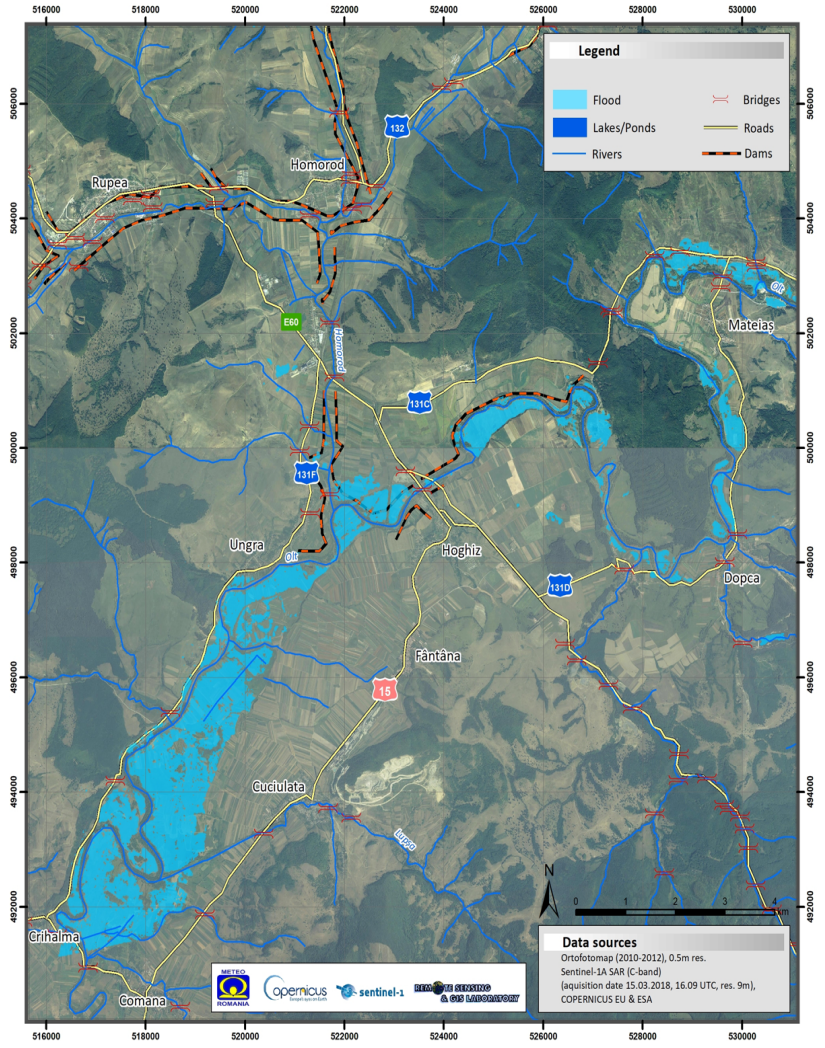

Figure 10. Floods on Olt River between Comana and Mateias (14 March 2018)

In Figure 11 it is represented the flood evolution from March 14 until March 19 on the Olt river, between Comana and Mateias settlements. It can be observed that after 6 days after the heavy rains, the flood still covered large surfaces of terrain.

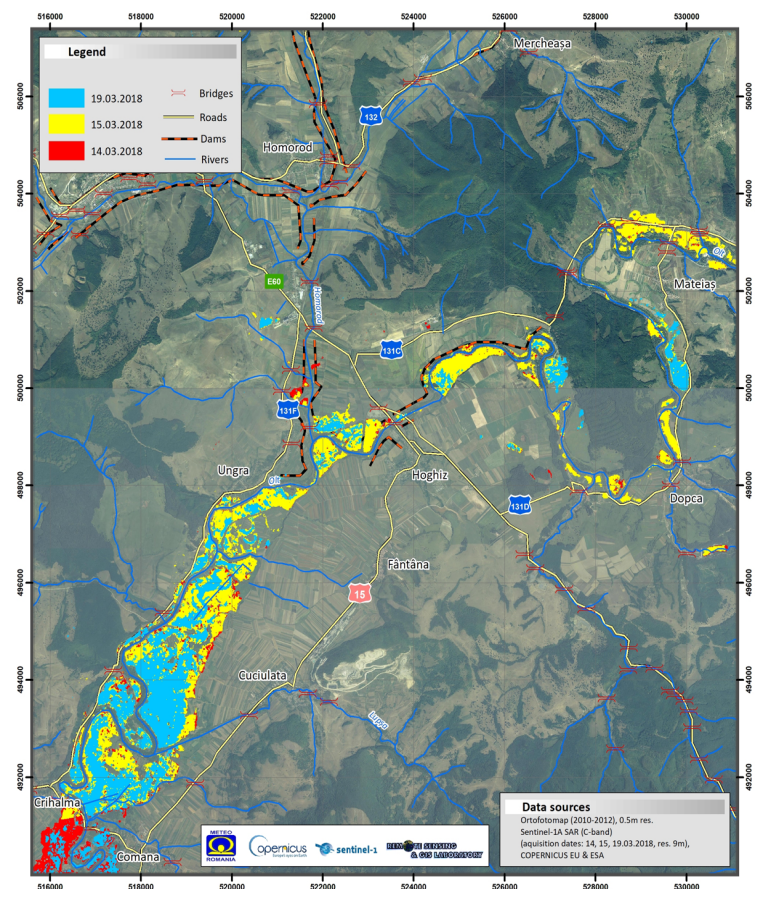

Figure 11. Evolution of floods on River Olt upstream of Comana (14-19 March 2018) 


\section{Conclusions}

The main problem for flood monitoring is associated with to the determination of the extent of it. The use of remote sensing offers a general view over the area affected by flood with satisfactory temporal and spatial resolution. The flood extent information, extracted from satellite data, can be used by decision makers during the flood phase (flood monitoring), the pre-flood phase (risk management) and the post-flood phase (for damage assessment).

The advantage of using the SAR measurements, for flood monitoring, is its independence of daytime and weather conditions. This is mainly due to the fact that water surface has strong contrast in the backscatter values and appears black in SAR imagery. Anyway, SAR images need corrections and filtering processes. Both VH and VV polarizations are suitable for flood detection and mapping with the mention that VV polarization have better results in detecting partially underwater structures and damage assessment. For reducing the speckle, commonly, the Lee's filters are used because they can remove the speckle better, but Gamma Map filter can have better performance.

The present study aims to analyze Sentinel-1 SAR data (of the European Earth Observation mission) for its potential to map flood extent over the upper part of the Olt basin, located in the central part of Romania, during the flood events on March 2018. The histogram thresholding methodology was used for flood monitoring at a necessary spatial resolution derived from Sentinel-1 SAR images. The Sentinel-1 GRD SAR images with spatial resolution of $10 \mathrm{~m}$ by $10 \mathrm{~m}$, meteorological and hydrological (water level/discharge) data were used for the purpose of flood monitoring for March 2018.

The histogram-threshold technique is based on a simple and fast process that discriminates flooded areas from those that are not, based on backscatter values in permanent waters and in flooded areas. The $-15 \mathrm{~dB}$ and $25 \mathrm{~dB}$ are the most representative values of the presence of water for both polarizations.

The flood monitoring using Sentinel-1 SAR data proved to be an effective method to get quick and precise overview of flooded areas. In this study, timely and detailed analysis had been carried out using Remote Sensing \& GIS tools (ESA SNAP and ArcGIS) for locating and identifying flooded areas under various seasons in the year of 2018 .

The obtained results contributed to a rapid assessment of the flood extent, without field work, and a rapid damage assessment, useful for disaster management to coordinate the first responders and other activities related to response and rehabilitation of damaged infrastructure in a quick manner.

The total surface affected by flood, occurred on Rivers Olt and his tributary Raul Negru, was over 2200 ha. From the perspective of land cover: arable land-1554 ha, pasture557 ha and other minor surfaces of vineyards, forests and urban areas (only $0.65 \mathrm{ha}$ ). The settlements were less affected mainly because of the dikes system, build in certain location on the River Olt and some other rivers from his hydrographic basin with flood risk.

\section{References}

1. Amitrano, D., Guida, R. and G. Ruello (2019). Multitemporal SAR RGB Processing for Sentinel-1 GRD Products: Methodology and Applications. IEEE J. Select. Top. Appl. Earth Obs. Remote Sens., 12, 1497-1507.

2. Bioresita, F., Puissant, A., A. Stumf and J-P. Malet (2018). A method for automatic and rapid mapping of water surfaces from Sentinel-1 imagery, Remote Sensing, 10 (2), 217.

3. Brisco, B., Schmitt, A., Murnaghan, K., Kaya, S., Roth, A. (2013). SAR polarimetric change detection for flooded vegetation. Int. J. Digital Earth, 6(2), 103-114.

4. Caballero, I., J. Ruiz and G. Navarro (2019), Sentinel2 satellite provide near-real time evaluation of catastrophic floods in the West Mediterranean. Water, 11 (12), 2499.

5. Carreño Conde, F. and M. De Mata Muñoz (2019) Flood Monitoring Based on the Study of Sentinel-1 SAR Images: The Ebro River Case Study. Water, 11, 2454.

6. Crăciunescu, V., Flueraru, C., G. Stăncălie, and A. Irimescu (2009). Developing a rapid mapping and monitoring service for flood management using remote sensing techniques in Flood Risk Management: Research and Practice, eds: Samuels, P., Huntington, S., Allsop, W., Harrop, J., Ed. Taylor \& Francis Group, London, UK, 237-243.

7. Crăciunescu, V., Stăncălie, G., Irimescu, A., Catană, S., Mihăilescu, D., Nerţan, A., G. Morcov, and S. Constantinescu (2016). Multi-scale multi-parametric platform for mapping of flood affected areas. Case study: 2006 Danube extreme flood in Romania. $J$. Hydrol Hydromech, 64 (4), 329-336.

8. CRED. Natural Disasters 2018. Brussels: CRED; 2019. Available at: https://emdat.be/sites/default/files/adsr 2018.pdf/.

9. D’Addabbo, A., Refice, A., Pasquariello, G., Lovergine, F. P., Capolongo, D., and S. Manfreda, (2016). A Bayesian Network for Flood Detection Combining SAR Imagery and Ancillary Data. IEEE Trans. Geosci. Remote Sensing, 54, 3612-3625.

10. DeVries, B., Hunag, C., Armston, J., Huang, W., J.W. Jones and M.W. Lang (2020). Rapid and robust monitoring of flood events using Sentinel-1 and Landsat data on the Google Earth Engine, Remote Sensing of Environment, 240, 111664.

11. EEA (2010). Mapping the impacts of natural hazards and technological accidents in Europe. An overview of the last decade, EEA Technical Report 13, 64-73.

12. European Commission (2007). Directive 2007/60/EC of the European Parliament and of the Council of 23 October 2007 on the assessment and management of flood risks. Off. J. Eur. Union L. 288, 27-34.

13. EM-DAT: The Emergency Events Database Universite catholique de Louvain (UCL) - CRED, D. Guha-Sapir - www.emdat.be, Brussels, Belgium.

14. Gan, T.Y., Zunic, F., Kuo, C.C. and T. Strobl (2012). Flood mapping of Danube River at Romania using 
single and multi-date ERS2-SAR images. Int. J. Appl. Earth Obs. Geoinform., 18, 69-81.

15. Giustarini, L., Hostache, R., Matgen, P., Schumann, G., D. Bates, P. C. and D. Mason (2013). A Change Detection Approach to Flood Mapping in Urban Areas Using TerraSAR-X. IEEE Trans. Geosci. Remote Sensing, 51, 2417-2430.

16. Horritt, M.S., Mason, D.C. and A.J. Luckman (2001). Flood boundary delineation from synthetic aperture radar imagery using a statistical active contour model. Int. J. Remote Sens., 22 (13), 2489-2507.

17. Huang, S., Cai, X., Chen, C. and D. Liu (2011). Change detection method based on fractal model and wavelet transform for multi-temporal SAR images. Int. J. Appl. Earth Obs. Geoinform., 13, 863-872.

18. ICPDR: http://www.icpdr.org/icpdr-files/15180

19. Inglada, J. and G. Mercier (2007). A new statistical similarity measure for change detection in multitemporal SAR images and its extension to multiscale change analysis. IEEE Trans. Geosci.Remote Sens., 45, 1432-1445.

20. IPCC (2014). Climate Change 2014: Synthesis Report. Contribution of Working Groups I, II and III to the Fifth Assessment Report of the Intergovernmental Panel on Climate Change [Core Writing Team, R.K. Pachauri and L.A. Meyer (eds.)]. IPCC, Geneva, Switzerland, $151 \mathrm{pp}$.

21. Irimescu, A., Stăncălie, G., Crăciunescu V., C. Flueraru, and E. Anderson (2009). The use of Remote Sensing and GIS techniques in flood monitoring and damage assessment: A study case in Romania in Threats to global water security, eds: Jones, A., Vardanian, T., Hakopian, C., NATO Science for Peace and Security Series C: Environmental Security, Ed. Springer, 167-177.

22. Joyce, K.E., Belliss, S.E., Samsonov, S.V., S.J. McNeill and P.J. Glassey (2009). A review of the status of satellite remote sensing and image processing techniques for mapping natural hazards and disasters. Prog. Phys. Geogr., 33, 183-207.

23. Jongman, B., Ward, P.J. and J.C. Aerts (2012). Global exposure to river and coastal flooding: Long term trends and changes. Glob. Environ. Change, 22, 823835.

24. Kussul, N., Shelestov, A. and S. Skakun (2008). Grid system for flood extent extraction from satellite images. Earth Sci. Inform., 1, 105-117.

25. Long, S., Fatoyinbo, T. E. and F. Policelli (2014). Flood extent mapping for Namibia using change detection and thresholding with SAR. Environ. Research Lett., 9, 035002.

26. Martinis, S., Twele, A. and S. Voigt (2009). Towards operational near real-time flood detection using a split-based automatic thresholding procedure on high resolution TerraSAR-X data. Natural Hazards and Earth System Science, 9, 303-314.

27. Martinis, S., Kersten, J. and A. Twele (2015). A fully automated TerraSAR-X based flood service. ISPRS J. Photogrammetry Remote Sensing, 104, 203-212.

28. Martinis, S. (2017). Improving flood mapping in arid areas using Sentinel-1 time series data. Proceedings of the 2017 International Geoscience and Remote Sensing Symposium, Fort Worth, TX, USA, 193-196.

29. Matgen, P., Hostache, R., Schumann, G., Pfister, L., Hoffman, L. and H. Savenije (2011). Towards an automated SAR-based floodmonitoring system: lessons learned from two case studies. Phys.Chem. Earth, 36, 241-252.

30. Nandi, I., P.K. Srivastava and K. Shah (2017). Floodplain Mapping through Support Vector Machine and Optical/Infrared Images from Landsat 8 OLI/TIRS Sensors: Case Study from Varanasi. Water Resour. Manag., 31, 1157-1171.

31. National Institute of Hydrology and Water Management (INHGA): http://www.inhga.ro/.

32. Negula, I., Crăciunescu, V., Vîrsta, A., Badea, A., Moise, C., Manea, R., M. Călin, and A. Irimescu, (2013). Downstream Copernicus Service for emergency management in Romania, Proceedings of the $13^{\text {th }}$ SGEM GeoConference on Informatics, Geoinformatics and Remote Sensing, 1, 403-410.

33. Neundlinger, M. (2012). Disaster Ahead: How Danube Floods Created Telegraph Networks. Environment \& Society Portal, Arcadia, 7. Rachel Carson Center for Environment and Society. $10.5282 / \mathrm{rcc} / 3747$.

34. NMA: National Meteorological Administration database.

35. Perrou, T., Garioud, A., and I. Parcharidis (2018). Use of Sentinel-1 imagery for flood management reservoir-regulated river basin. Front. Earth Sci., 12, 506-520.

36. Pirrone, D., Bovolo, F. and L. Bruzzone (2016). A novel framework for change detection in bi-temporal polarimetric SAR images. Image and Signal Processing for Remote Sensing XXII, 100040Z.

37. Refice, A., Capolongo, D., Pasquariello, G., Daaddabbo, A., Bovenga, F., Nutricato, R., Lovergine, F. P. and L. Pietranera (2014). SAR and InSAR for flood monitoring: Examples with COSMO-SkyMed data. IEEE J. Selected Topics Applied Earth Observations Remote Sensing, 7 (7), 2711-2722.

38. Reksten, J.H., Salberg, A.-B. and R. Solberg (2019). Flood detection in Norway based on Sentinel-1 SAR imagery. The International Archives of the Photogrammetry, Remote Sensing and Spatial Information Sciences, XLII-3/W8, 349-355.

39. ROWATER: http://rowater.ro/daolt

40. Schmidt, K., Schwerdt, M., Nuno, M and J. Reimann (2020), Radiometric Comparison within the Sentinel1 SAR Constellation over a Wide Backscatter Range, Remote Sens., 12, 854.

41. Schumann, G. (2017). Remote sensing of floods, Oxford Research Encyclopedia of Natural Hazard Science. 10.1093/acrefore/9780199389407.013.265.

42. Serpico, S. B., Dellepiane, S., Boni, G., Moser, G., Angiati, E. and R. Rudari (2012). Information extraction from remote sensing images for flood monitoring and damage evaluation. Proc. IEEE, 100 (10), 2946-2970.

43. Shen, X., Wang, D., Mao, K., E. Anagnostou and Y. Hong (2019). Inundation Extent Mapping by 
Synthetic Aperture Radar: A Review. Remote Sensing, 11, 879.

44. Stăncălie, G., V. Crăciunescu, and A. Irimescu, (2009), Spatial data integration for emergency services of flood management in Threats to global water security, edits: Jones, A., Vardanian, T., Hakopian, C., NATO Science for Peace and Security Series C: Environmental Security, Ed. Springer, 155165.

45. Stăncălie, G., V. Crăciunescu, and A. Irimescu, (2016). Development of a downstream emergency response service for flood and related risks in Romania based on satellite data, Proceedings of the $3^{\text {rd }}$ European Conference on Flood Risk Management: Innovation, Implementation, Integration, 7, 14891496.

46. Szopos, N.M. and B. Czellecz (2017). Hugh water level observations along the upper course of the Olt River (Romania) from a hydrological modelling aspect. Landscape \&Environment, 11 (2), 10-19.
Sentiel-1 data in flood mapping in urban areas: Ankara (Turkey) 2018 floods. Int. Arch. Photogramm. Remote Sens. Spatial Inf. Sci., XLII-5, 575-581.

48. Twele, A., Cao, W., S. Plank and S. Martinis (2016). Sentinel-1-based flood mapping: A fully automated processing chain. Int. J. Remote Sens., 37 (13), 2990 3004.

49. Uddin, K., Matin, M.A. and F. Meyer (2019). Operational flood mapping using multi-temporal Sentinel-1 SAR images: A case study from Bangladesh, Remote Sensing, 11, 1581.

50. UN-SPIDER: http://www.un-spider.org/advisorysupport/recommended-practices/recommendedpractice-flood-mapping-and-damage-assessment
47. Tavus, B., Kocaman, S., C. Gokceoglu, and H.A. Nefeslioglu (2018). Consideration on the use of 